\title{
Pengembangan Modul Fisika Berbasis Visual untuk Sekolah Menengah Atas (SMA)
}

\author{
Fauzi Bakria), Razali Rasyid, Rina Dwi A. Mulyaningsih \\ Program Studi Pendidikan Fisika, Fakultas MIPA, Universitas Negeri Jakarta \\ Email: a)fauzi_bakri@yahoo.co.id
}

\begin{abstract}
This study aims to produce teaching materials of physics in the form of visual-based for High School grade 12. This research use research and development methods, with ADDIE steps: requirements analysis, design module design, drafting module, the finalization of the module, product validation, product trials and product revision. The results carried out by an expert modules media based on questionnaire received an average percentage of $85.18 \%$, while conducted by subject matter experts based on the questionnaire received an average percentage of $80.42 \%$, and conducted by experts of learning resources based on questionnaires received the average percentage of $87.50 \%$. The results of empirical testing by teachers using a questionnaire which gets an average percentage of $81.35 \%$, while that is done by the students based on the questionnaire received an average percentage of $83.82 \%$. The overall results indicate that these modules can be used as a source of learning in learning physics.
\end{abstract}

Keywords: the visual media, module, research development

\begin{abstract}
Abstrak
Penelitian ini bertujuan untuk menghasilkan produk bahan ajar fisika dalam bentuk modul fisika berbasis visual untuk Sekolah Menengah Atas kelas XII semester 1. Metode yang digunakan dalam penelitian ini adalah metode penelitian pengembangan (research and development), dengan langkah-langkah ADDIE yaitu analisis kebutuhan, perancangan desain modul, penyusunan naskah/ draft modul, finalisasi modul, validasi produk, uji coba produk dan revisi produk. Hasil uji kelayakan modul yang dilakukan oleh ahli media berdasarkan angket mendapat rata-rata persentase sebesar $85,18 \%$, sedangkan yang dilakukan oleh ahli materi berdasarkan angket mendapat rata-rata persentase sebesar $80,42 \%$ serta yang dilakukan oleh ahli sumber belajar berdasarkan angket mendapat rata-rata persentase sebesar $87,50 \%$. Hasil uji empirik oleh guru berdasarkan angket mendapat rata-rata persentase sebesar $81,35 \%$ sedangkan yang dilakukan oleh siswa berdasarkan angket mendapat rata-rata persentase sebesar $83,82 \%$. Hasil ini secara keseluruhan menunjukkan bahwa modul ini dapat digunakan sebagai salah satu sumber belajar dalam pembelajaran fisika.
\end{abstract}

Kata-kata kunci: media visual, modul, penelitian pengembangan 


\section{PENDAHULUAN}

Pada umumnya guru menggunakan buku teks sebagai media pembelajaran bagi siswanya. Keterbatasan waktu pembelajaran di sekolah juga mengharuskan siswa belajar mandiri di rumah baik sebelum maupun sesudah pembelajaran di kelas. Pada umumnya siswa mengalami kesulitan dalam memahami materi yang disampaikan dalam buku teks yang mereka miliki sehingga banyak siswa yang tidak melakukan pembelajaran sebelum pembelajaran di kelas. Siswa membutuhkan bahan ajar yang udah dipahami dan memungkinkan mereka untuk belajar secara mandiri sesuai kemampuan dirinya. Oleh karena itu, perlu dikembangkan suatu media pembelajaran berupa modul fisika berbasis visual untuk kelas XII.

Modul yang dibuat akan menyajikan materi fisika dengan ditunjang visualisasi berupa gambar, diagram, bagan yang disajikan berwarna sehingga membuat siswa merasa tertarik untuk membacanya. Penyajian materi dalam modul diharapkan siswa tidak berbelit-belit sehingga memudahkan mereka memahami konsep dan materi. Modul juga diharapkan menyajikan contoh kasus dan soal dengan penyelesaian untuk membantu memudahkan mereka memahami konsep yang dipelajari.

Modul adalah bahan ajar yang dapat digunakan oleh siswa untuk belajar secara mandiri dengan bantuan seminimal mungkin dari guru, yang tersusun secara sistematis dan terdiri dari rangkaian kegiatan belajar (Purwanto dkk 2007; Andi 2011; Asyhar 2011). Pembelajaran menggunakan modul memberikan beberapa keuntungan antara lain: (1) Memberikan feedback atau balikan yang segera, (2) Dapat disesuaikan dengan kemampuan siswa secara individual dengan memberikan keleluasaan dalam menentukan kecepatan mempelajarinya, bentuk maupun bahan pelajaran, (3) Setelah dilakukan evaluasi, guru dan siswa akan mengetahui pada bagian modul yang mana siswa telah berhasil dan pada bagian modul yang mana belum berhasil mencapai tujuan pembelajaran, (4) Siswa mencapai hasil sesuai dengan kemampuannya.

Media visual adalah alat-alat yang dapat digunakan untuk menyampaikan materi ajar dari sumber belajar menuju pembelajar yang semata-mata mengandalkan indera penglihatan (Asyhar 2011; Munadi 2010). Peranan media visual dalam proses belajar juga dikemukakan oleh Arsyad (2011) antara lain: (1) memperlancar pemahaman, (2) memperkuat ingatan, (3) menumbuhkan minat siswa, dan (4) memberikan hubungan antara isi materi pelajaran dengan dunia nyata.

\section{METODOLOGI PENELITIAN}

Penelitian ini bertujuan untuk menghasilkan produk bahan ajar fisika berupa modul fisika berbasis visual, untuk sekolah menengah atas kelas XII semester 1. Metode penelitian yang digunakan dalam penelitian ini adalah metode penelitian pengembangan (research and development). Metode ini dipilih untuk menghasilkan sebuah produk dalam bidang pendidikan. Produk yang dikembangkan adalah bahan ajar fisika berupa modul fisika berbasis visual, untuk sekolah menengah atas kelas XII semester 1.

Langkah-langkah yang digunakan dalam proses penyusunan modul ini menggunakan pendekatan ADDIE yaitu Analyze, Design, Develop, Implement, Evaluate (Branch, 2009), dengan pengembangan langkah menjadi :

1. Analisis kebutuhan

2. Penyusunan desain modul

3. Penyusunan naskah/ draft modul

4. Finalisasi modul

5. Validasi produk

6. Uji coba produk

7. Revisi produk

Adapun instrumen yang digunakan pada penelitian ini berupa angket yang menggunakan skala likert untuk keperluan analisis kebutuhan, validasi produk dan uji coba produk. 


\section{HASIL DAN PEMBAHASAN}

Berdasarkan data yang diperoleh saat analisis kebutuhan yang dilakukan di SMAN 2 Tambun Selatan, SMAN 102 Jakarta dan SMAN 1 Tambun Selatan dengan jumlah total responden sebanyak 82 siswa, maka disusunlah draft modul. Dalam hal ini draft modul berisi materi fisika kelas XII Semester 1. Berikut ini adalah potongan beberapa bagian modul yang dikembangkan:

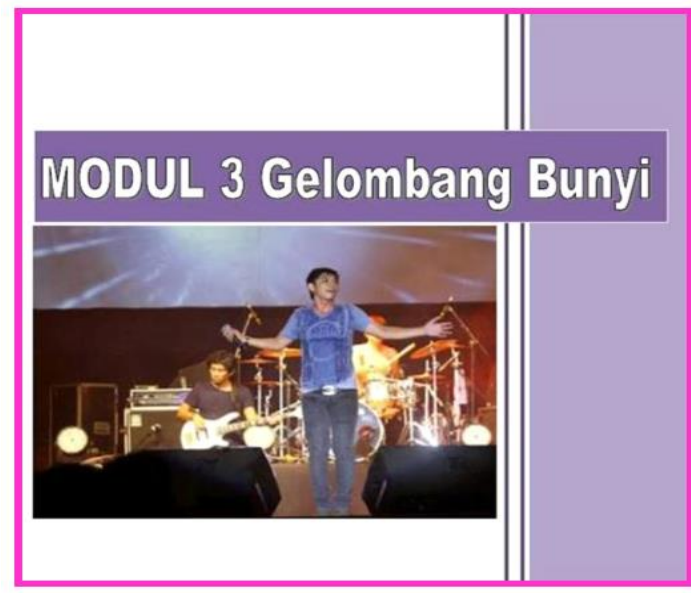

GAMBAR 1. Sampul modul.

Kegiatan Belajar 1
Karakteristik, Klasifikasi, Cepat
rambat, dan Sifat-sifat Gelombang
Bunyi
I Standar Kompetensi:
I Menerapkan konsep dan prinsip gejala gelombang dalam
I menyelesaikan masalah
I Kompetensi Dasar:
I Mendeskripsikan gejala dan ciri-ciri gelombang bunyi serta
I menerapkan konsep dan prinsip gelombang bunyi dalam teknologi

GAMBAR 2. Bagian isi modul.

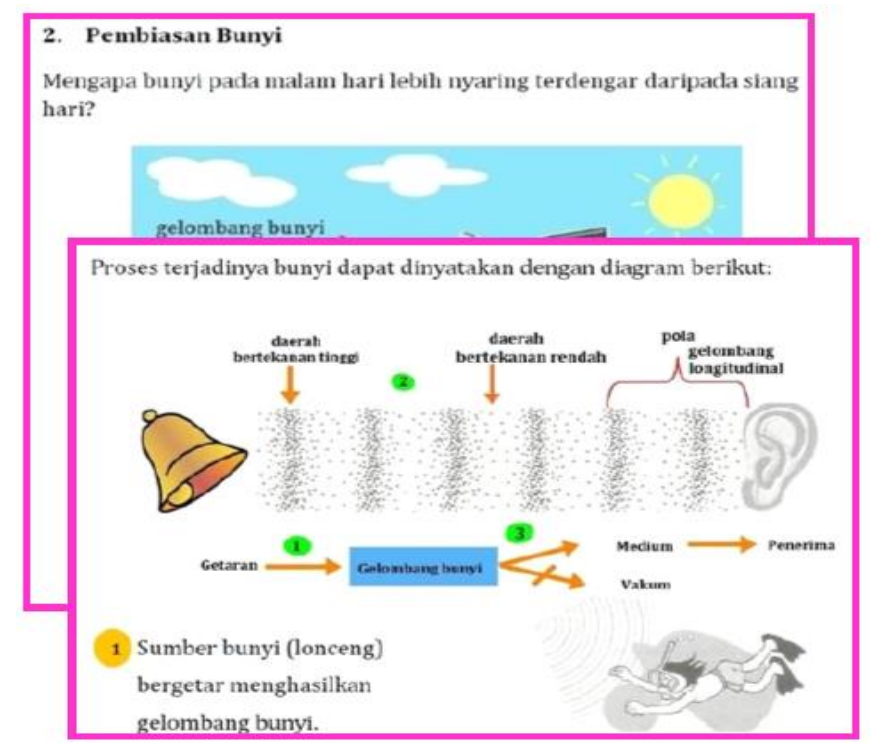

GAMBAR 3. Uraian Materi. 


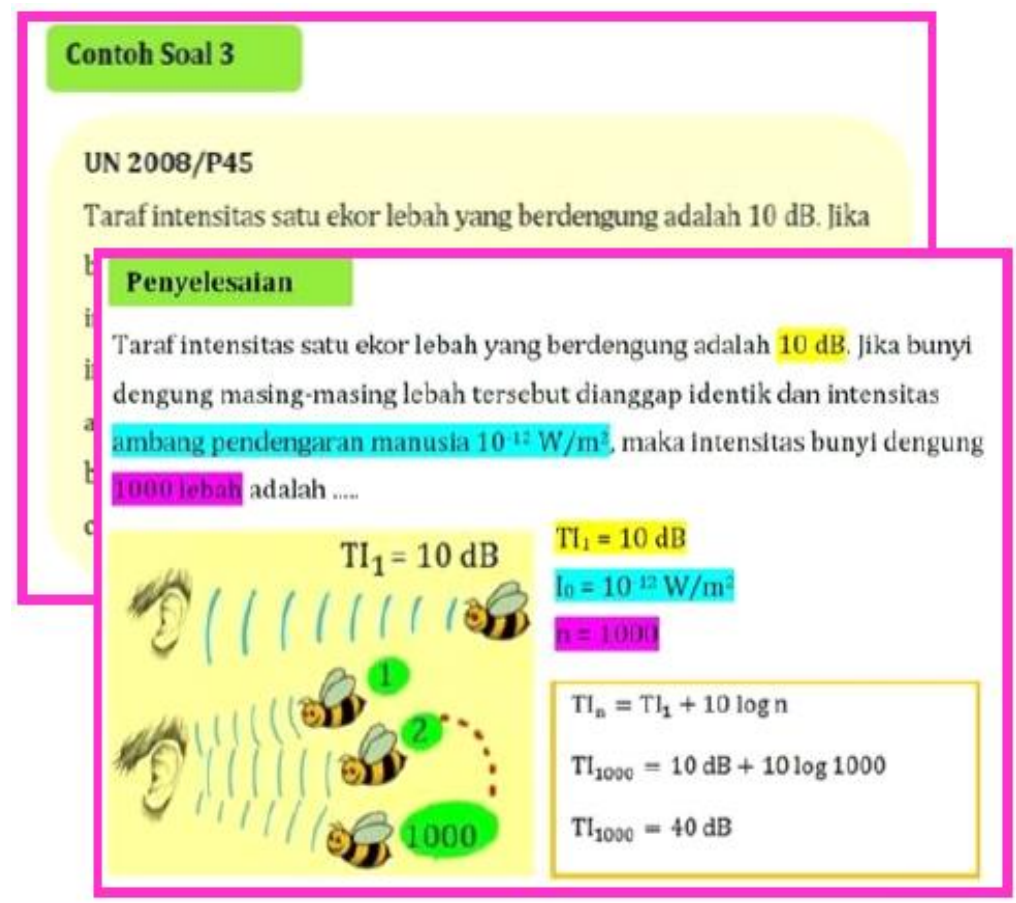

GAMBAR 4. Contoh Soal.

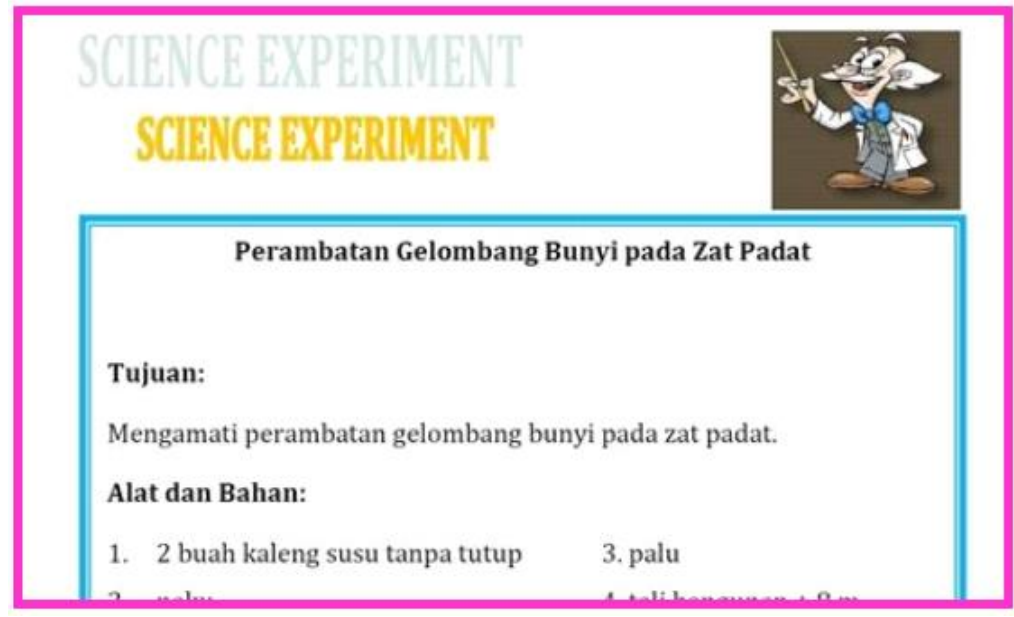

GAMBAR 5. Science Experiment.

\section{Rangkuman}

- Bunyi merupakan gelombang longitudinal. Kecepatan bunyi tergantung pada medium yang dilaluinya dan temperatur.

- Syarat terjadinya bunyi:
1. Ada sumber bunyi
2. Ada pendengar
3. Ada medium

- Berdasarkan rentang frekuensinya, bunyi dibagi menjadi 3 yaitu

GAMBAR 6. Rangkuman materi. 


\section{Medan Tempur 1}

1. Perhatikan gambar kelelawar berikut.

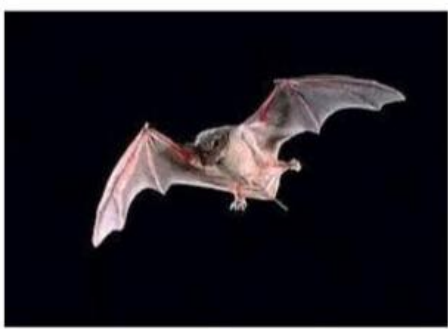

GAMBAR 7. Medan tempur.

\section{Tes Formatif 1}

1. Berilah tanda silang ( $x$ ) pada huruf $a, b, c, d$ atau e pada jawaban yang tepat:

1. Pernyataan berikut berkaitan dengan sifat-sifat gelombang bunyt:
(1) gelombang transversal
(3) gelombang mekanik

2. UN $2008 / \mathrm{P} 04$

Seorang penonton pada lomba balap mobil mendengar bunyi (deru

mohill vano herheda ketika mnhil mendekat dan meniauh Rata.mata

Cocokan jawahanmu dengan menggunakan kunci jawaban Tes

Formatif 1 yang terdapat di bagian akhir Modul 3. Hitunglah jawabanmu yang benar, kemudian gunakan rumus di bawah ini untuk mengetahui tingkat penguasaanmu terhadap materi Kegiatan Belajar 1.

Tingkat penguasaan $=\frac{\text { Jumlah jawabanmu yang benar }}{5} \times 100 \%$

Arti tingkat penguasaan yang kamu capal adalah sebagai berikut:

$90 \%-100 \%$ - batk sekalt

8ก\% $89 \%$ = haik

GAMBAR 8. Test Formatif.

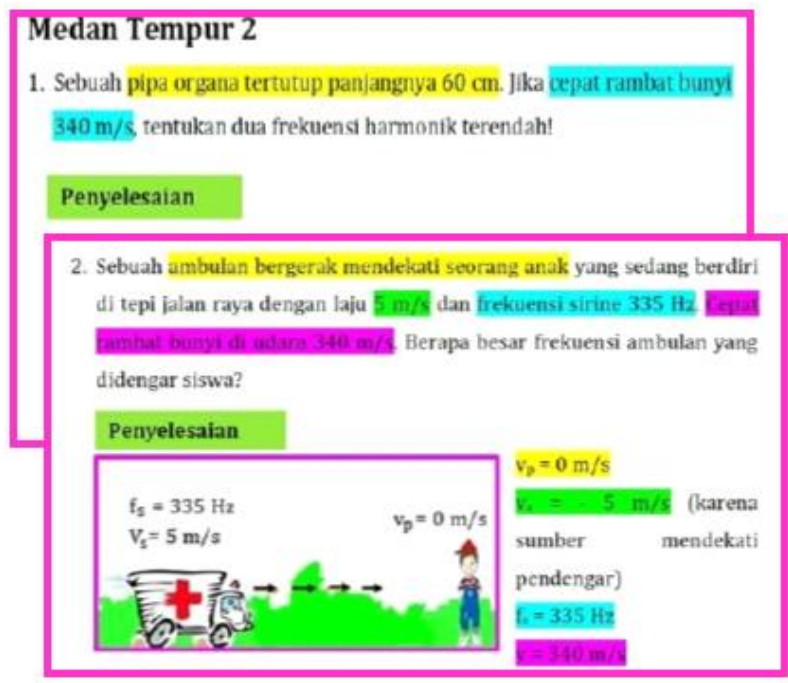

GAMBAR 9. Kunci jawaban. 
Setelah proses penyusunan modul fisika berbasis visual selesai maka dilakukan validasi produk. Validasi produk ini terdiri dari validasi ahli media, validasi ahli materi dan validasi ahli sumber belajar. Validasi kelayakan media dilakukan oleh 3 ahli yaitu 1 dosen Teknologi Pendidikan FIP UNJ serta 2 dosen Fisika FMIPA UNJ, validasi kelayakan materi dilakukan pada 3 ahli yaitu dosen Fisika FMIPA UNJ sedangkan validasi kelayakan sumber belajar dilakukan oleh 1 ahli yaitu dosen Fisika FMIPA UNJ. Tahapan validasi ini bertujuan untuk mengetahui kelayakan modul fisika berbasis visual yang dikembangkan dapat diterima sebagai media pembelajaran mandiri oleh siswa.

Validasi dilakukan dengan menggunakan angket yang dikembangkan dalam bentuk skala Likert dengan ketentuan skor sebagai berikut: skor $1=$ sangat kurang baik; skor $2=$ kurang baik; skor $3=$ baik; dan skor 4 = sangat baik. Kemudian data yang diperoleh dari penyebaran angket itu akan diolah dengan menggunakan rumus sebagai berikut:

$$
\text { Persentase Skor }=\frac{\sum \text { skor perolehan }}{\sum \text { skor maksimum }} \times 100 \%
$$

Dengan ketentuan interpretasi skor sebagai berikut: $0 \%-25 \%=$ sangat kurang baik; $26 \%-50 \%=$ kurang baik; $51 \%-75 \%$ = baik serta $76 \%-100 \%=$ sangat baik.

Ahli media memberikan penilaian bahwa modul yang digunakan sudah layak sebagai media pembelajaran fisika. Dari 6 indikator media yang dinilai, semuanya dinilai sangat baik.

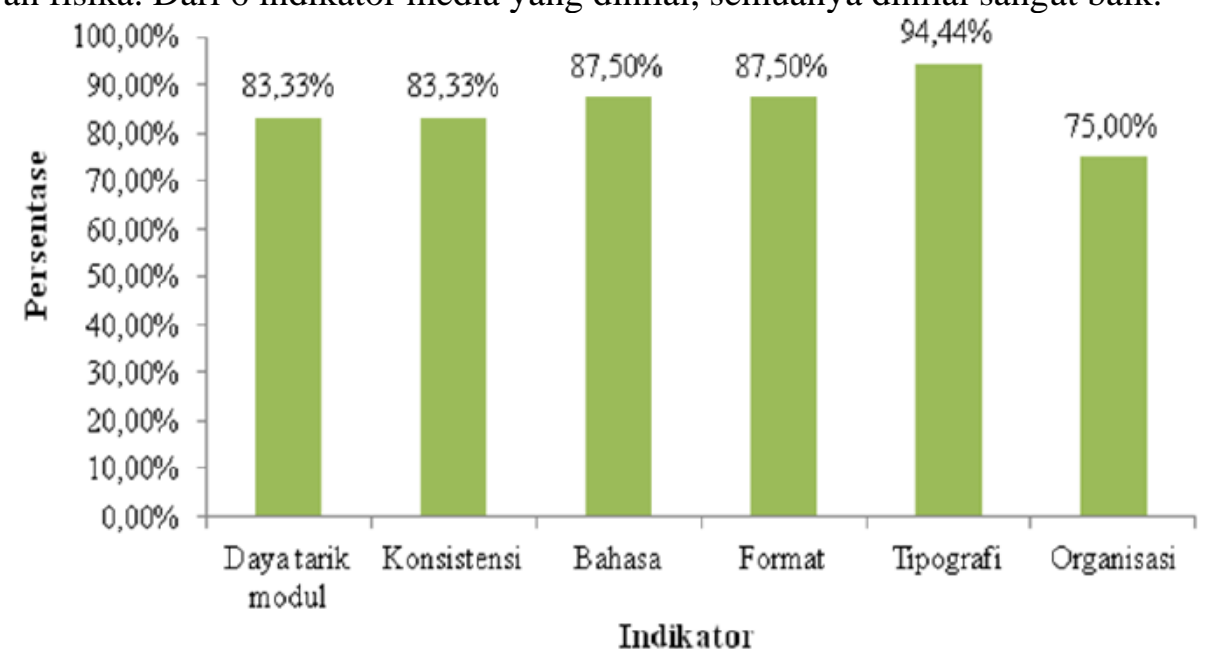

GAMBAR 10. Hasil validasi ahli media.

Ahli materi memberikan penilaian bahwa uraian materi pada modul yang sudah layak sehingga modul dapat digunakan sebagai media pembelajaran fisika. Dari 5 indikator media yang dinilai, semuanya dinilai sangat baik

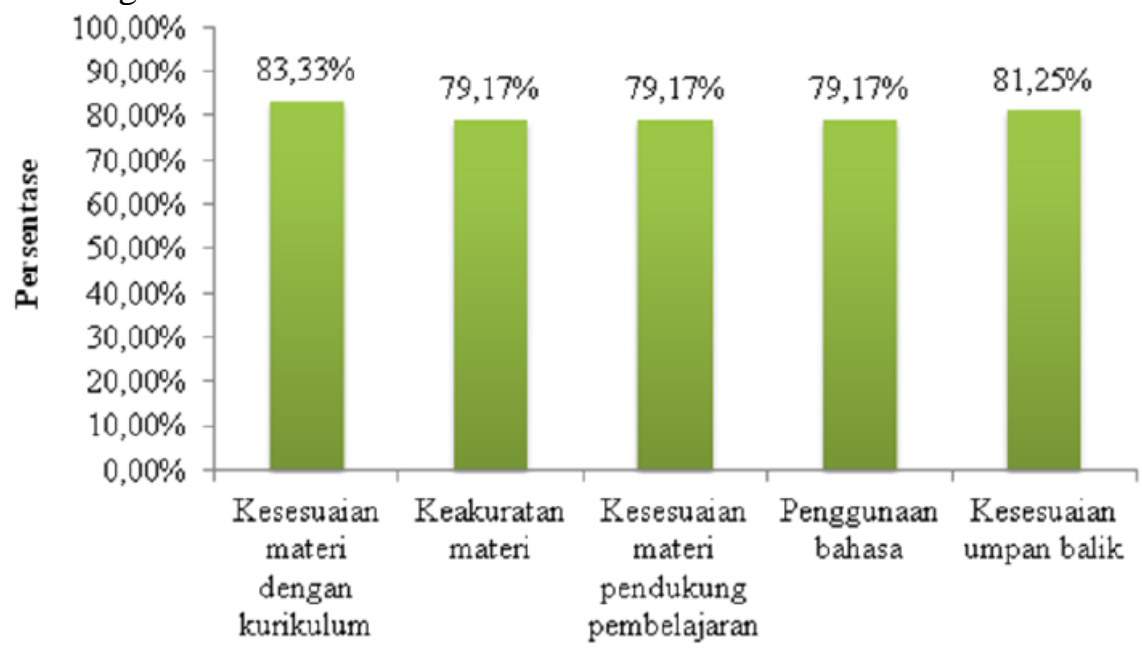

\section{Indikator}

GAMBAR 11. Hasil validasi ahli materi. 
Ahli sumber belajar memberikan penilaian bahwa modul yang dihasilkan sudah layak sebagai media pembelajaran fisika. Dari 6 indikator media yang dinilai, semuanya dinilai sangat baik

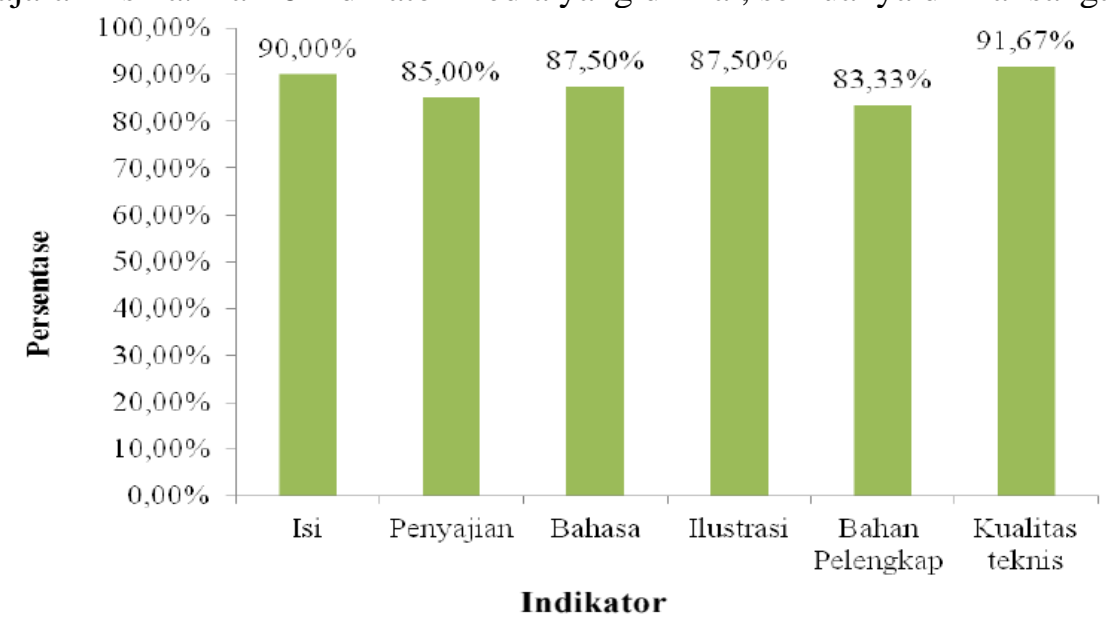

GAMBAR 12. Hasil validasi ahli sumber belajar.

Setelah diperbaiki sesuai saran dan kritik oleh ahli media, ahli materi dan ahli sumber belajar, maka modul fisika berbasis visual diujicobakan pada guru dan siswa di 3 sekolah, yaitu SMAN 2 Tambun Selatan, SMAN 102 Jakarta dan SMAN 1 Tambun Selatan.

Hasil uji empirik pada guru fisika memberikan penilaian bahwa modul yang digunakan sudah layak sebagai media pembelajaran fisika. Dari 7 indikator media yang dinilai, semuanya dinilai sangat baik

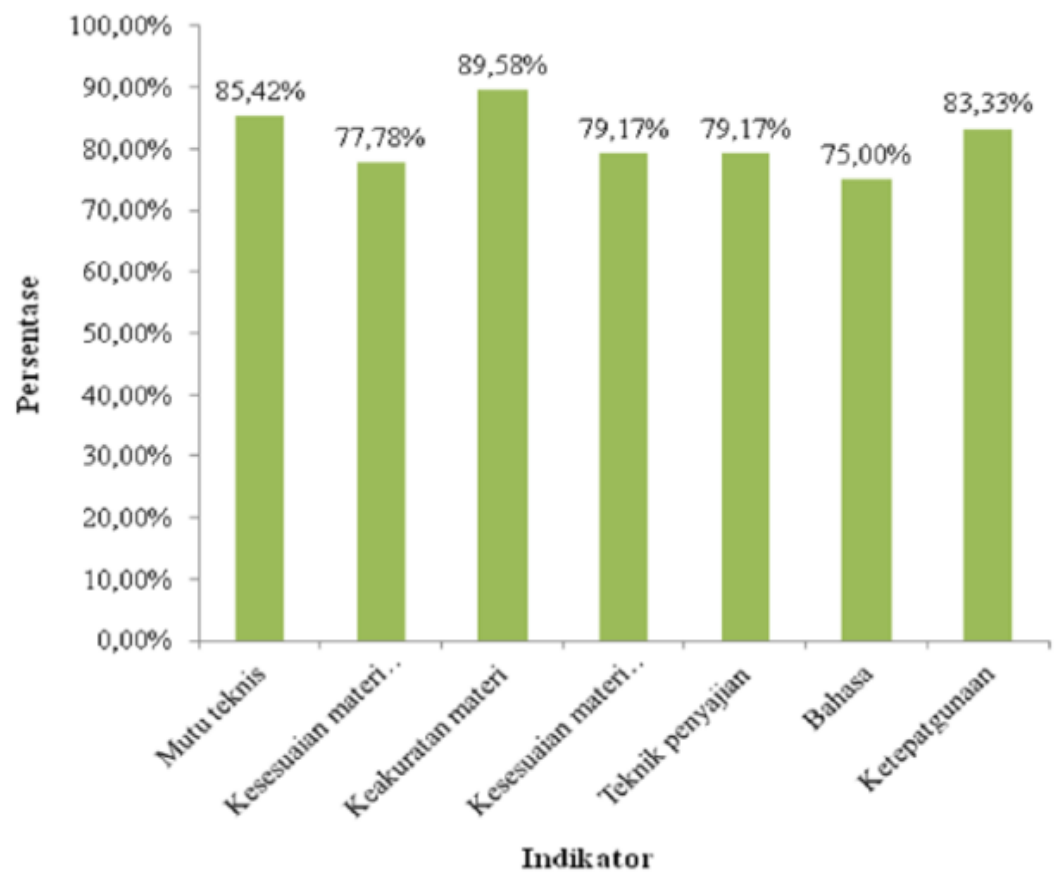

GAMBAR 13. Hasil uji empirik oleh guru fisika.

Hasil persentase rata-rata yang diperoleh saat validasi dari ahli media sebesar 85,18\% (sangat baik), dari ahli materi sebesar $80,42 \%$ (sangat baik) dan dari ahli sumber belajar sebesar $87,50 \%$ (sangat baik). Sedangkan yang diperoleh saat uji coba dari guru sebesar $81,35 \%$ (sangat baik) dan dari siswa sebesar $83,82 \%$ (sangat baik). 


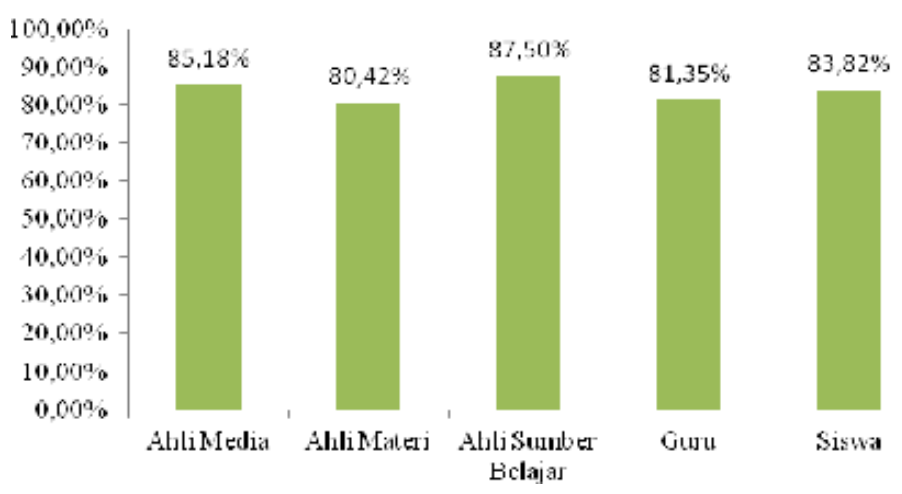

GAMBAR 14. Hasil penilaian akhir modul

Berdasarkan hasil penilaian yang dilakukan oleh ahli media, ahli materi dan ahli sumber belajar serta hasil uji coba yang dilakukan pada guru dan siswa, menunjukkan bahwa modul fisika berbasis visual yang dikembangkan sudah sangat baik, sehingga layak digunakan ebagai bahan ajar mandiri oleh siswa SMA.

\section{SIMPULAN DAN SARAN}

Modul fisika berbasis visual yang dikembangkan telah memenuhi syarat kelayakan sebagai sumber belajar dalam pembelajaran fisika. Hal ini berdasarkan hasil uji kelayakan modul fisika berbasis visual yang dilakukan oleh ahli media, ahli materi dan ahli sumber belajar serta hasil uji coba modul fisika berbasis visual yang dilakukan pada guru dan siswa yang menunjukkan bahwa modul fisika berbasis visual yang dikembangkan sudah sangat baik sebagai bahan belajar mandiri.

Berdasarkan proses dan hasil dari pengembangan modul fisika berbasis visual, penulis memiliki beberapa saran, yaitu: (1) Perlu dilakukan penelitian lanjutan untuk menguji efektivitas modul fisika berbasis visual dalam kegiatan belajar mengajar di kelas; (2) Perlu dikembangkan modul fisika berbasis visual untuk materi fisika lainnya

\section{DAFTAR PUSTAKA}

Arsyad, Azhar. 2011. Media Pembelajaran. Jakarta: Rajawali Press.

Asyhar, Rayandra. 2011. Kreatif Mengembangkan Media Pembelajaran. Jakarta: Gaung Persada Press.

Branch, Robert Maribe, 2009, Instructional Design: The ADDIE Approach, New York, Springer.

Munadi, Yudhi. 2010. Media Pembelajaran Sebuah Pendekatan Baru. Jakarta: Gaung Persada Press.

Prastowo, Andi. 2011. Panduan Kreatif Membuat Bahan Ajar Inovatif-Menciptakan Metode Pembelajaran yang Menarik dan Menyenangkan. Yogyakarta: DIVA Press.

Purwanto, dkk. 2007. Pengembangan Modul. Jakarta: Departemen Pendidikan Nasional Pusat Teknologi Informasi dan Komunikasi Pendidikan. 